\title{
REPRESENTAÇÕES SOCIAIS SOBRE A EDUCAÇÃO ESPECIAL/EDUCAÇÃO INCLUSIVA: Revisão da Literatura (2008-2018)
}

\author{
Orliney Maciel Guimarães ${ }^{1}$ \\ Gabrielly Fuji Messias Nagatomy²
}

\begin{abstract}
RESUMO
Este artigo apresenta uma revisão sistemática de literatura sobre as Representações Sociais (RSs) sobre a Educação Especial (EE)/Educação Inclusiva (EI) referente ao período de 2008-2018. A base de dados foi o Catálogo de Dissertações e Teses da Capes e os periódicos da área de Educação disponíveis on-line e classificados no Qualis/Capes. Foi possível constatar que essas pesquisas vêm crescendo nos últimos anos e as têm sido produzidas em todas as regiões do Brasil, em universidades públicas, estaduais e privadas. A maior parte das produções emprega a abordagem qualitativa com pesquisa de campo e, para a constituição e análise de dados, utiliza-se de entrevistas e da Análise de Conteúdo, respectivamente. Os participantes das pesquisas são, em sua maioria, professores em formação inicial e do Ensino Superior. Os objetivos das pesquisas abordam as RSs sobre os processos de inclusão de alunos com deficiência ou as RSs sobre os aspectos que definem a inserção de um aluno na EE. Os resultados das pesquisas realizadas apontaram, em sua maioria, que as Representações Sociais não favorecem a inclusão e que as principais barreiras são a acessibilidade atitudinal e a de procedimentos educacionais. Os resultados desta revisão endossam a relevância das representações sociais para estudos sobre EE/EI.
\end{abstract}

Palavras-chave: Revisão sistemática. Inclusão. Teoria das Representações Sociais.

\section{SOCIAL REPRESENTATIONS OF SPECIAL EDUCATION/INCLUSIVE EDUCATION: LITERATURE REVIEW (2008-2018)}

\section{ABSTRACT}

This article is a systematic review of the literature on Social Representations (SR) of Special Education (SE)/Inclusive Education (IE) for the 2008-2018 period. The database was the Capes Dissertations and Theses Catalog and journals in the area of Education available online and classified in the Qualis/Capes. It was possible to verify that these researches have increased in recent years, also that they have been produced in all regions of Brazil, being carried out in public, state and private universities. Most of them use a qualitative approach with field research and, for the constitution and analysis of data, they use interviews and Content Analysis, respectively. Research participants are mostly teachers in initial training and higher education professors. The research objectives address the SR of the processes involved in the inclusion of students with disabilities or the SR of the aspects that define the insertion of a SE student. The results showed, mostly, that the SR found do not favor inclusion, and that the main barriers are attitudinal and methodological accessibility. This review endorses the relevance of SR for studies on SE/IE.

Keywords: Systematic Review. Inclusion. Social Representations Theory.

Recebido em: 7/5/2020

Aceito em: $16 / 7 / 2020$

\footnotetext{
1 Autora correspondente. Universidade Federal do Paraná - Setor de Ciências Exatas, Departamento de Química. Centro Politécnico. Jardim das Américas. CEP 81531-990. Curitiba/PR, Brasil. http://lattes.cnpq.br/4387421271761881. https://orcid.org/0000-0003-4762-4884. orli. guimaraes@gmail.com

2 Universidade Federal do Paraná. Curitiba/PR, Brasil. http://lattes.cnpq.br/1458039787954558. https://orcid.org/0000-0003-0250-3050.
} 
O presente estudo faz parte de uma pesquisa exploratória referente a uma dissertação de Mestrado, cujo objetivo é analisar a Representação Social (RS) de alunos de Licenciatura em Química sobre Educação Especial/Educação Inclusiva de uma Instituição de Ensino Superior.

Historicamente os diferentes tipos de atendimentos reservados às pessoas com deficiência foram construídos socialmente, e ainda hoje são compartilhados pelos diferentes grupos sociais. Destaca-se que o público da Educação Especial (EE) foi historicamente compreendido por representações pejorativas, de maneira que a Pessoa Com Deficiência $(P C D)$ desde a Antiguidade até a era pré-cristã foi excluída, colocada à margem da sociedade e exterminada com a justificativa de punição divina (VASCONCELLOS; SANTOS; ALMEIDA, 2011). Tais concepções vinculadas à crenças e valores foram se dissipando e dando lugar às urgências trazidas pelo sistema econômico resultante da revolução burguesa no século 15 , fator que não favoreceu essas pessoas, as quais foram consideradas pela sociedade como economicamente improdutivas (DECHICHI, 2001).

Com o passar dos anos a PCD foi ganhando espaço na sociedade em sistemas assitencialistas e segregativos e o modelo médico de atendimento perpetuou-se de maneira que a deficiência foi encarada como doença que necessitava de tratamento, observando-se que apenas no século 19 teve início o ingresso de crianças em escolas especiais e classes especiais (VASCONCELLOS; SANTOS; ALMEIDA, 2011). Desde então vários movimentos ao redor do mundo vêm lutando para que esse público tenha a garantia e efetivação de direitos.

No Brasil a inclusão ocorreu de forma a acompanhar os movimentos mundiais com características próprias do país, de maneira que hoje, para atendimento aos alunos com Necessidades Educacionais Especiais (NEE), são oferecidos dois tipos de serviço, os quais foram se constituindo historicamente e têm se unificado: a EE e a Educação Inclusiva (EI). Segundo Mazzotta (1996, p. 11) a EE é

[...] um conjunto de recursos e serviços educacionais especiais organizados para apoiar, suplementar e, em alguns casos, substituir os serviços educacionais comuns, de modo a garantir a educação formal dos educandos que apresentem necessidades educacionais muito diferentes das da maioria das crianças e jovens (MAZZOTTA, 1996, p. 11).

Já a El envolve processos de escolarização que incluem as pessoas com NEE em contextos regulares, independentemente do nível de atendimento que elas necessitem, como explica Sassaki (1998, p. 8):

Educação inclusiva é o processo que ocorre em escolas de qualquer nível preparadas para propiciar um ensino de qualidade a todos os alunos independentemente de seus atributos pessoais, inteligências, estilos de aprendizagem e necessidades comuns ou especiais. A inclusão escolar é uma forma de inserção em que a escola comum tradicional é modificada para ser capaz de acolher qualquer aluno incondicionalmente e de propiciar-lhe uma educação de qualidade. Na inclusão, as pessoas com deficiência estudam na escola que frequentariam se não fossem deficientes.

Ambos os atendimentos têm por público-alvo os educandos com deficiência, transtornos globais do desenvolvimento e altas habilidades ou superdotação (BRASIL, 1996). 
Embora muito tenha se alcançado em questões de direitos, a sua efetivação ainda é um desafio, uma vez que concepções de senso comum disseminadas na História da humanidade influenciaram e ainda influenciam na maneira como a pessoa com NEE é atendida e compreendida nos dias atuais. Dessa forma, repensar a EE no sentido de uma El vai além da conquista de direitos, requer uma quebra de paradigmas.

Entre os desafios que a EE enfrenta, Sassaki (2009) discute dimensões de acessibilidade em nível de lazer, trabalho e educação diante da concepção dos paradigmas da inclusão. São elas: arquitetônica, comunicacional, metodológica, instrumental, programática e atitudinal.

Dessas dimensões destaca-se a Dimensão Atitudinal, a qual no campo da educação engloba diversas atitudes que vão contra mitos do senso comum envolvidos na $E E$, segundo Sassaki (2009):

Realização de atividades de sensibilização e conscientização, promovidas dentro e fora da escola a fim de eliminar preconceitos, estigmas e estereótipos, e estimular a convivência com alunos que tenham as mais diversas características atípicas (deficiência, síndrome, etnia, condição social, etc.) para que todos aprendam a evitar comportamentos discriminatórios (SASSAKI, 2009, p. 6, grifo nosso).

Nessa mesma perspectiva, Nozi (2013) analisa os saberes docentes, recomendados pela produção acadêmica, para promover a inclusão de alunos com NEE no sistema regular de ensino, e a dimensão mais abordada, entre os trabalhos analisados, foi também a Acessibilidade Atitudinal, reforçando a importância dessa dimensão para enfrentar os paradigmas da inclusão.

Diante do exposto, percebe-se que a EE/EI se estabeleceu entre diversos fatores sociais que influenciaram e ainda são discutidos em estudos na área. Acreditamos que muitos dos desafios enfrentados pela EE/EI podem ser compreendidos e debatidos a partir do entendimento das representações sociais que os indivíduos carregam em razão dos diferentes tipos de relações interpessoais estabelecidas ao longo da vida, visto que, como explica Glat (2018, p. 10):

[...] para fazer frente às atuais expectativas, mais do que desenvolver novos métodos e propostas de atendimento, precisamos desconstruir a visão estereotipada de incapacidade, de dependência e de limitação que sempre marcou - aberta ou veladamente - o tratamento que conferimos a nossos alunos e clientes.

Nesse sentido, Moscovici (1978) investigou como o imaginário social, advindo de concepções do senso comum, influencia a forma como a sociedade trata e divulga opiniões sobre um determinado tema, e denominou essas concepções de Representações Sociais (RS).

A representação social é definida como "uma forma de conhecimento, socialmente elaborada e compartilhada, que tem um objetivo prático e concorre para a construção de uma realidade comum a um conjunto social" (JODELET, 2001, p. 22). Ela trata de verdadeiras "teorias" do senso comum, de maneira que tem por função tornar o "não familiar" em algo "familiar". 
Na área da educação, a Teoria das RS (TRS) vem sendo utilizada, segundo Gilly (2002), por se constituir em um "campo privilegiado para ver como se constroem, evoluem e se transformam as representações sociais no seio de grupos sociais, e nos esclarecer sobre o papel dessas construções nas relações desses grupos com o objeto de sua representação" (p. 233).

$\mathrm{Na} \mathrm{EE} / \mathrm{El}$ as representações sociais tornam-se um campo rico para estudo, visto que, durante a História da humanidade, ela se mostrou complexa e polêmica. Segundo Almeida e Naiff (2011, p. 32), "não produzimos representações sociais de qualquer fenômeno. Somente aqueles que nos incomodam nos forçam a um posicionamento e nos remetem a partilhar saberes".

Dessa forma, o objetivo deste estudo foi realizar uma revisão sistemática das produções acadêmico-científicas que abordam as RSs sobre EE/EI, de modo a compreender como a representação social de professores e/ou futuros professores pode influenciar os processos de inclusão vivenciados por alunos com NEE.

\section{METODOLOGIA DA PESQUISA}

Com o objetivo de analisar e discutir as produções acadêmico-científicas sobre as RSs e EE/El, foi realizado um levantamento bibliográfico de teses, dissertações e artigos empreendendo uma sucinta análise das produções com inspiração nos estudos realizados nas pesquisas denominadas "estado da arte".

O levantamento bibliográfico, segundo Lakatos e Marconi (2003, p. 142), "[...] é um apanhado geral sobre os principais trabalhos já realizados, revestidos de importância, por serem capazes de fornecer dados atuais e relevantes relacionados ao tema". Dessa forma, ao realizar esse levantamento, pode-se obter uma visão amplificada das pesquisas a respeito dos processos de RSs sobre EE/EI no cenário atual.

Sobre os procedimentos adotados, realizou-se o levantamento bibliográfico de acordo com as fases propostas para um estudo de estado da arte, apoiando-se nos trabalhos de Megid Neto (1999) e de Romanowski e Ens (2006) e estabelecendo algumas etapas, como relacionado a seguir, e caracterizadas ao longo do texto: i) Definição de um tema/objeto/problemática; ii) Definição de descritores para busca nas bases de dados; iii) Definição do intervalo de tempo a ser considerado nas buscas nas bases de dados; iv) Definição das bases de dados a serem consultadas; v) Definição de critérios de seleção entre os trabalhos encontrados; vi) Definição dos critérios de análise dos trabalhos; vii) Análise e avaliação dos trabalhos selecionados e viii) Escrita do relatório.

Visto a necessidade de realizar alguns recortes (espaciais e temporais) para possibilitar a análise das RSs no contexto da EE/EI, foram selecionados artigos da área de Educação de revistas avaliadas no sistema Qualis Capes nos estratos A1, A2 e B1 do Quadriênio 2013-2016; e as dissertações e teses sobre as RSs e EE/EI, na base de dados do Banco de Teses da Capes.

A etapa de levantamento bibliográfico de teses e dissertações e dos artigos ocorreu em junho de 2019. Nessa busca foram utilizados algumas expressões como: "Representação social; Representações Sociais, Serge Moscovici, Educação Especial". Ainda na plataforma da Capes foram selecionadas as áreas de conhecimentos: Direitos especiais; 
Educação; Educação Especial, visto a abrangência de resultados para todas as áreas. A busca dos artigos foi realizada nos sites eletrônicos dos periódicos on-line acessando os volumes publicados de cada revista.

Posteriormente realizou-se um recorte temporal das produções no período de 2008 a 2019, tendo em vista que em 2008 houve a publicação da Política Nacional de Educação Especial na Perspectiva da Educação Inclusiva (BRASIL, 2008), que trouxe bases reflexivas para uma educação pautada na inclusão.

A seleção dos trabalhos foi realizada por meio da análise dos títulos, palavras-chave e leitura dos resumos, fase caracterizada por pré-análise, como explica Godoy (1995, p. 24), "normalmente envolve a leitura 'flutuante', ou seja, um primeiro contato com os documentos, o exame inicial da documentação que nos permitirá definir, com mais acuidade, quais documentos são mais promissores para se analisar esse problema".

Visto a especificidade da temática, selecionou-se primeiramente os trabalhos sobre educação e RS; destes, foram selecionados aqueles que continham em seu título, resumo e/ou palavras-chave os termos: EE/El, deficiência, e ainda, aqueles que citavam o público-alvo da EE, PCD, transtornos da mente e altas habilidades/superdotação.

Desta maneira, foram encontradas 60 produções entre dissertações, teses e artigos, as quais foram analisadas primeiramente com base em descritores institucionais. De acordo com Megid Neto e Carvalho (2018), estes tipos de descritores compreendem os dados sobre: autor do trabalho, ano de publicação, local de desenvolvimento da pesquisa para teses e dissertações, instituição, entre outros. E, posteriormente, foram analisados os descritores de base específica, que segundo esses mesmos autores possibilitam investigar as tendências mais específicas das produções, tais como: natureza e tipo de pesquisa, instrumentos de constituição de dados, tipo de análise, participantes da pesquisa, objetivos dos trabalhos e principais resultados encontrados. Estes dois últimos descritores foram analisados por meio de análise de conteúdo de Bardin (2016).

Segundo Oliveira (2008), a análise de conteúdo é constituída por várias técnicas em que se procura descrever o conteúdo enunciado no processo de comunicação por meio de desenvolvimentos sistemáticos; no caso desta pesquisa, utilizou-se a metodologia da análise categorial, a qual consiste em três etapas: i) Pré-análise; ii) Seleção das unidades de análise (ou unidades de significado) e iii) Processo de categorização e subcategorização (BARDIN, 2016), observando-se que as categorias emergiram da leitura das produções.

\section{ANÁLISE DA PRODUÇÃO ACADÊMICA SOBRE A REPRESENTAÇÃO SOCIAL E A EDUCAÇÃO ESPECIAL/INCLUSIVA}

No Quadro 1 são apresentados os 60 trabalhos encontrados e analisados neste artigo, o ano de publicação, título e autor(res) das produções, assim como as siglas de identificação: a pesquisa totalizou 32 dissertações (D), 12 teses (T) e 16 (A) artigos acadêmico-científicos, nas bases de dados utilizadas. 
Quadro 1 - Dissertações, Teses e artigos sobre RS sobre a EE/EI (2008-2018)

\begin{tabular}{|c|c|c|c|}
\hline SIGLA & ANO & TÍTULO & AUTORES(AS) \\
\hline D1 & 2008 & $\begin{array}{l}\text { Representações sociais de professores sobre a inclusão de } \\
\text { alunos com deficiência em turmas regulares }\end{array}$ & $\begin{array}{l}\text { Cristiane Correia } \\
\text { Taveira }\end{array}$ \\
\hline D2 & 2008 & $\begin{array}{l}\text { Representações sociais de professores sobre formação } \\
\text { continuada em educação especial }\end{array}$ & $\begin{array}{l}\text { Simone do Socorro } \\
\text { Freitas do Nascimento }\end{array}$ \\
\hline D3 & 2008 & $\begin{array}{c}\text { Inclusão escolar: Um olhar para a diversidade: as } \\
\text { representações sociais de professores do ensino } \\
\text { fundamental da rede pública sobre o aluno com } \\
\text { necessidades educacionais especiais }\end{array}$ & $\begin{array}{l}\text { Vília Mariza Fraga } \\
\text { Modesto }\end{array}$ \\
\hline D4 & 2009 & $\begin{array}{c}\text { Inclusão Educacional de crianças com deficiência no } \\
\text { município de João Pessoa: As representações sociais das } \\
\text { mães }\end{array}$ & $\begin{array}{l}\text { Francymara Antonino } \\
\text { Nunes Assis }\end{array}$ \\
\hline D5 & 2009 & $\begin{array}{l}\text { Representação social sobre educação inclusiva por } \\
\text { professores de Cruzeiro do Sul - Acre }\end{array}$ & $\begin{array}{l}\text { Ademarcia Lopes de } \\
\text { Oliveira Costa }\end{array}$ \\
\hline D6 & 2009 & $\begin{array}{l}\text { Representações sociais dos alunos de educação física da } \\
\text { UFPE sobre a disciplina Educação Física Adaptada }\end{array}$ & $\begin{array}{l}\text { Onassis Ferreira dos } \\
\text { Santos }\end{array}$ \\
\hline D7 & 2010 & $\begin{array}{l}\text { Representações Sociais de professores sobre a inclusão } \\
\text { escolar de educandos com necessidades educacionais } \\
\text { especiais }\end{array}$ & Roseane Rabelo Souza \\
\hline D8 & 2011 & $\begin{array}{l}\text { As representações sociais dos participantes do curso Letras } \\
\qquad- \text { Libras/EaD sobre surdos }\end{array}$ & $\begin{array}{l}\text { Simone de Fátima } \\
\text { Saldanha Carneiro } \\
\text { Costa }\end{array}$ \\
\hline D9 & 2011 & $\begin{array}{c}\text { Surdez e Inserção Profissional: representações sociais de } \\
\text { universitários surdos }\end{array}$ & $\begin{array}{c}\text { José Carlos Miraglia } \\
\text { Magaldi }\end{array}$ \\
\hline D10 & 2011 & $\begin{array}{c}\text { As representações sociais de professores do ensino } \\
\text { fundamental sobre o aluno surdo: a [in]visibilidade na } \\
\text { inclusão escola }\end{array}$ & Andréa Pereira Silveira \\
\hline D11 & 2011 & $\begin{array}{l}\text { As representações docentes sobre os estudantes incluídos } \\
\text { nos cursos do IF Sul-Rio-Grandense, campus Charqueadas }\end{array}$ & $\begin{array}{c}\text { Andreia Cabral Colares } \\
\text { Pereira }\end{array}$ \\
\hline D12 & 2012 & $\begin{array}{l}\text { Representações sociais de um grupo de professores sobre a } \\
\text { educação inclusiva }\end{array}$ & $\begin{array}{l}\text { Renata Cristina } \\
\text { Domingos de Souza } \\
\text { Lima }\end{array}$ \\
\hline D13 & 2012 & $\begin{array}{l}\text { Inclusão no ensino superior: um estudo das representações } \\
\text { sociais dos acadêmicos com deficiência visual da UFPB }\end{array}$ & Raphaela de Lima Cruz \\
\hline D14 & 2013 & $\begin{array}{l}\text { Indicadores das representações sociais da superdotação na } \\
\text { discursividade das professoras }\end{array}$ & $\begin{array}{l}\text { Caroline Leonhardt } \\
\text { Romanowski }\end{array}$ \\
\hline D15 & 2013 & $\begin{array}{c}\text { A escolarização do estudante com deficiência intelectual } \\
\text { nas representações sociais de professores de Ensino Médio }\end{array}$ & Katia Rosa Azevedo \\
\hline D16 & 2014 & $\begin{array}{l}\text { O instituído e o vivido na formação docente para a } \\
\text { Educação Inclusiva: Representações sociais de professores } \\
\text { egressos do Curso de Licenciatura em Biologia do IFPA }\end{array}$ & $\begin{array}{l}\text { Ermelina Nóbrega De } \\
\text { Magalhães Melo }\end{array}$ \\
\hline D17 & 2014 & $\begin{array}{l}\text { Representações sociais de discentes do curso letras de } \\
\text { libras da Uepa acerca da pessoa surda }\end{array}$ & $\begin{array}{l}\text { Cyntia Franca } \\
\text { Cavalcante De } \\
\text { Andrade Da Silva }\end{array}$ \\
\hline D18 & 2015 & $\begin{array}{c}\text { Educação inclusiva e representação social: Os desafios } \\
\text { subjetivos para a realização do processo de ensino- } \\
\text { aprendizagem e de sociabilidade }\end{array}$ & $\begin{array}{l}\text { Nathalia Sayuri } \\
\text { Yamada }\end{array}$ \\
\hline D19 & 2015 & $\begin{array}{l}\text { Representações Sociais de educandos surdos sobre a } \\
\text { atuação do Intérprete Educacional no Ensino Superior }\end{array}$ & $\begin{array}{l}\text { Waldma Maíra } \\
\text { Menezes de Oliveira }\end{array}$ \\
\hline D20 & 2015 & $\begin{array}{l}\text { Representações sociais de professoras a respeito do } \\
\text { atendimento educacional especializado para alunos surdos }\end{array}$ & $\begin{array}{l}\text { Huber Kline Guedes } \\
\text { Lobato }\end{array}$ \\
\hline D21 & 2016 & $\begin{array}{l}\text { Representações sociais de professores sobre inclusão e o } \\
\text { projeto político-pedagógico: a escola em movimento }\end{array}$ & $\begin{array}{c}\text { Mariana Paula Pereira } \\
\text { Scavoni }\end{array}$ \\
\hline
\end{tabular}




\begin{tabular}{|c|c|c|c|}
\hline D22 & 2016 & $\begin{array}{l}\text { Representações sociais acerca da educação inclusiva } \\
\text { na formação inicial de professores: Um estudo com } \\
\text { licenciandos-bolsistas Pibid de uma Licenciatura em Química }\end{array}$ & $\begin{array}{l}\text { Camila Pereira De } \\
\text { Camargo }\end{array}$ \\
\hline D23 & 2016 & $\begin{array}{c}\text { Representação social dos professores de aluno com autismo } \\
\text { sobre os processos de ensino e aprendizagem }\end{array}$ & $\begin{array}{l}\text { Claudia Elci Bervig } \\
\text { Lemos }\end{array}$ \\
\hline D24 & 2016 & $\begin{array}{c}\text { Representações sociais e práticas docentes no IFSP: A } \\
\text { educação de pessoas com deficiência }\end{array}$ & $\begin{array}{l}\text { Claudia Abboud } \\
\text { Aranega }\end{array}$ \\
\hline D25 & 2016 & Representações de professores sobre a inclusão escolar & Ana Paula Abdalla \\
\hline D26 & 2017 & $\begin{array}{l}\text { Representações sociais de professores do Ensino } \\
\text { Fundamental I em exercício: os sentidos no contexto da(s) } \\
\text { diferença(s) }\end{array}$ & $\begin{array}{l}\text { Emille Gomes } \\
\text { Paganotti }\end{array}$ \\
\hline D27 & 2017 & $\begin{array}{l}\text { Pesquisa em educação inclusiva: Representações dos } \\
\text { docentes das salas de recursos multifuncionais sobre o } \\
\text { professor- pesquisador }\end{array}$ & $\begin{array}{l}\text { Eline Freitas Brandao } \\
\text { Barbosa }\end{array}$ \\
\hline D28 & 2017 & $\begin{array}{l}\text { O processo de inclusão: Objetivação e Ancoragem do } \\
\text { primeiro aluno surdo numa instituição de Ensino Superior }\end{array}$ & $\begin{array}{c}\text { Elza Maria do Socorro } \\
\text { da Silva }\end{array}$ \\
\hline D29 & 2017 & $\begin{array}{l}\text { A gênese das representações sociais sobre o trabalho do } \\
\text { segundo professor na perspectiva da educação inclusiva }\end{array}$ & Natália Silveira Lima \\
\hline D30 & 2017 & $\begin{array}{l}\text { As representações sociais: como elas moldam a realidade } \\
\text { surda }\end{array}$ & Louise Mesquita Costa \\
\hline D31 & 2018 & $\begin{array}{l}\text { Perspectivas de futuro profissional das pessoas com } \\
\text { deficiência e com necessidades educacionais específicas }\end{array}$ & $\begin{array}{c}\text { Elisângela Leles } \\
\text { Lamonier }\end{array}$ \\
\hline D32 & 2018 & $\begin{array}{c}\text { Representações sociais de tecnologia assistiva de } \\
\text { professores e responsáveis por alunos com deficiência } \\
\text { visual }\end{array}$ & $\begin{array}{l}\text { Thiago Parreira } \\
\text { Sardenberg Soares }\end{array}$ \\
\hline $\mathrm{T} 1$ & 2008 & $\begin{array}{c}\text { Criatividade e inclusão na formação de professores: } \\
\text { Representações e Práticas Sociais }\end{array}$ & $\begin{array}{l}\text { Kátia Regina Xavier da } \\
\text { Silva } \\
\end{array}$ \\
\hline $\mathrm{T} 2$ & 2010 & $\begin{array}{l}\text { Formas do trabalho docente em duas escolas especiais de } \\
\text { surdos: estudos históricos e de representações sociais }\end{array}$ & $\begin{array}{c}\text { Jose Anchieta de } \\
\text { Oliveira Bentes }\end{array}$ \\
\hline T3 & 2014 & $\begin{array}{c}\text { Formação Continuada e Representação Social: Implicações } \\
\text { para a Educação Inclusiva }\end{array}$ & $\begin{array}{c}\text { Ademarcia Lopes de } \\
\text { Oliveira Costa }\end{array}$ \\
\hline $\mathrm{T} 4$ & 2015 & $\begin{array}{c}\text { Representações docentes: o olhar para o aluno com } \\
\text { mucopolissacaridade tipo VI do município de Monte Santo } \\
\text { - Bahia }\end{array}$ & $\begin{array}{l}\text { Cristina Bressaglia } \\
\quad \text { Lucon }\end{array}$ \\
\hline T5 & 2015 & $\begin{array}{c}\text { Representações Sociais de Professores Acerca da Inclusão } \\
\text { Escolar: Elementos para uma discussão das práticas de } \\
\text { ensino }\end{array}$ & $\begin{array}{l}\text { Antonio Eugenio } \\
\text { Cunha }\end{array}$ \\
\hline T6 & 2015 & $\begin{array}{c}\text { Inclusão de pessoas com deficiência na educação superior: } \\
\text { Representações Sociais que produzem sentidos e (re) } \\
\text { desenham cenários }\end{array}$ & $\begin{array}{l}\text { Denise de Oliveira } \\
\quad \text { Alves }\end{array}$ \\
\hline $\mathrm{T} 7$ & 2015 & $\begin{array}{l}\text { A pessoa com deficiência física: Representações sociais } \\
\text { de alunos de cadeiras de rodas sobre a escolarização e as } \\
\text { implicações no processo formativo }\end{array}$ & $\begin{array}{c}\text { Neide Maria } \\
\text { Fernandes Rodrigues } \\
\text { de Sousa }\end{array}$ \\
\hline T8 & 2016 & $\begin{array}{l}\text { As representações sociais de pessoa com deficiência dos } \\
\text { estudantes dos cursos de Pedagogia: quando a educação } \\
\text { inclusiva interroga a formação docente }\end{array}$ & $\begin{array}{l}\text { Mariana Paula Pereira } \\
\text { Scavoni }\end{array}$ \\
\hline T9 & 2016 & $\begin{array}{l}\text { Sinais de escolarização e as repercussões nos projetos de } \\
\text { vida: Representações sociais de universitários surdos }\end{array}$ & $\begin{array}{l}\text { Arlete Marinho } \\
\text { Gonçalves }\end{array}$ \\
\hline $\mathrm{T} 10$ & 2017 & $\begin{array}{l}\text { A Deficiência Intelectual Nos Discursos e nas práticas de } \\
\text { jovens nativos na Pedagogia de orientação inclusiva: Um } \\
\text { estudo em representações sociais }\end{array}$ & Katia Rosa Azevedo \\
\hline T11 & 2017 & $\begin{array}{l}\text { A Representação Social dos professores de surdos sobre o } \\
\text { ensino de libras e língua portuguesa no ensino fundamental }\end{array}$ & $\begin{array}{l}\text { Sandra Regina Leite de } \\
\text { Campos }\end{array}$ \\
\hline
\end{tabular}




\begin{tabular}{|c|c|c|c|}
\hline T12 & 2018 & $\begin{array}{c}\text { Representações sociais sobre inclusão na formação inicial } \\
\text { de professores Niterói - RJ } 2018 \\
\end{array}$ & $\begin{array}{l}\text { Sandra Cristina } \\
\text { Moraes de Souza }\end{array}$ \\
\hline A1 & 2009 & $\begin{array}{c}\text { "Sem amor não se consegue desenvolver um bom trabalho" } \\
\text { análise das representações sociais de professoras sobre } \\
\text { inclusão escolar }\end{array}$ & $\begin{array}{l}\text { Edneia Rodrigues } \\
\text { Albuquerque; Laêda } \\
\text { Bezerra Machado }\end{array}$ \\
\hline $\mathrm{A} 2$ & 2010 & $\begin{array}{c}\text { Concepções de coordenadoras de CMEI e o paradigma da } \\
\text { inclusão na educação da primeira infância }\end{array}$ & $\begin{array}{l}\text { Nájela Tavares Ujiie; } \\
\text { Anizia Costa Zych }\end{array}$ \\
\hline A3 & 2010 & $\begin{array}{c}\text { O que pensam as crianças ouvintes a respeito da } \\
\text { inclusão de crianças surdas no estudo regular: um estudo } \\
\text { comparativo de crianças brasileiras de uma escola pública e } \\
\text { uma escola privada }\end{array}$ & \begin{tabular}{|c|} 
Beatriz Bargas Dorneles; \\
Virgínia Bedin; Isabel \\
Cristina Peregrina \\
Vasconcelos; Rosane da \\
Conceição Vargas \\
\end{tabular} \\
\hline A4 & 2010 & $\begin{array}{c}\text { Representações sociais de professores acerca do aluno } \\
\text { com deficiência: A prática educacional e o ideal do ajuste à } \\
\text { normalidade }\end{array}$ & $\begin{array}{c}\text { Carlo Ralph De Musis; } \\
\text { Sumaya Persona de } \\
\text { Carvalho }\end{array}$ \\
\hline A5 & 2011 & $\begin{array}{l}\text { As representações sociais dos licenciandos de física } \\
\text { referentes à inclusão de deficientes visuais }\end{array}$ & $\begin{array}{l}\text { Maria da Conceição de } \\
\text { Almeida Barbosa Lima; } \\
\text { Maria Auxiliadora } \\
\text { Delgado Machado }\end{array}$ \\
\hline A6 & 2011 & $\begin{array}{l}\text { A representação social do aluno com deficiência na } \\
\text { educação inclusiva: o olhar das crianças }\end{array}$ & \begin{tabular}{|c|} 
Karina Mendonça \\
Vasconcellos; Maria de \\
Fátima Souza Santos; \\
Angela Maria Oliveira \\
Almeida \\
\end{tabular} \\
\hline A7 & 2012 & $\begin{array}{l}\text { Representações Sociais dos Educadores de Infância e a } \\
\text { Inclusão de Alunos com Necessidades Educativas Especiais }\end{array}$ & $\begin{array}{l}\text { Francisca M. Rocha } \\
\text { Almas Fragoso; João } \\
\text { Casal }\end{array}$ \\
\hline A8 & 2012 & $\begin{array}{l}\text { Representações Sociais de Professores sobre o Autismo } \\
\qquad \text { Infantil }\end{array}$ & \begin{tabular}{|c} 
Michele Araújo Santos \\
e Maria de Fátima de \\
Souza Santos
\end{tabular} \\
\hline A9 & 2014 & $\begin{array}{c}\text { Crianças Indígenas Kaiowá e Guarani: Um estudo sobre as } \\
\text { representações sociais da deficiência }\end{array}$ & $\begin{array}{l}\text { Marilda Moraes } \\
\text { Garcia; Vânia Pereira } \\
\text { da Silva }\end{array}$ \\
\hline A10 & 2014 & $\begin{array}{l}\text { Dados de Investigação em Ciências da Educação e em Artes } \\
\text { Visuais: testemunho para a construção da Escola Inclusiva }\end{array}$ & $\begin{array}{l}\text { Maria Odete Emygdio } \\
\text { da Silva }\end{array}$ \\
\hline A11 & 2016 & $\begin{array}{l}\text { Narrativas autobiográficas de surdos ou de pessoas com } \\
\text { deficiência visual: Análise de identidade e representações }\end{array}$ & $\begin{array}{l}\text { Janete Inês Muller; } \\
\text { Felipe Leão Milanes }\end{array}$ \\
\hline A12 & 2017 & $\begin{array}{c}\text { Representações sociais do aluno portador de transtorno } \\
\text { mental e sua inclusão na escola: a visão de professores do } \\
\text { Ensino Fundamental }\end{array}$ & $\begin{array}{l}\text { Isabela Silveira de } \\
\text { Farias; Denise Freire } \\
\text { Teles Campos }\end{array}$ \\
\hline A13 & 2017 & $\begin{array}{l}\text { Pensamento social e educação: concepção de escola } \\
\text { e avaliação da inclusão por parte de mães de alunos } \\
\text { deficientes de São Gonçalo }\end{array}$ & $\begin{array}{c}\text { lelva Maria Costa de } \\
\text { Lima Ribeiro; Rafael } \\
\text { Moura Coelho Pecly } \\
\text { Wolter; Marsyl Bulkool } \\
\text { Mettrau }\end{array}$ \\
\hline A14 & 2018 & $\begin{array}{l}\text { Educação inclusiva e as representações dos estudantes } \\
\text { sobre seus pares com deficiência }\end{array}$ & $\begin{array}{l}\text { Molise de Bem } \\
\text { Magnabosco; } \\
\text { Leonardo Lemos De } \\
\text { Souza }\end{array}$ \\
\hline A15 & 2018 & $\begin{array}{l}\text { O olhar social da deficiência intelectual em escolas do } \\
\text { campo a partir dos conceitos de identidade e de diferença }\end{array}$ & $\begin{array}{c}\text { Debora Teresa Palma; } \\
\text { Relma Urel Carbone } \\
\text { Carneiro }\end{array}$ \\
\hline A16 & 2018 & $\begin{array}{c}\text { Desconstruindo Representações Sociais: Por uma Cultura de } \\
\text { Colaboração para Inclusão Escolar }\end{array}$ & Rosana Glat \\
\hline
\end{tabular}

Fonte: Organizado pelas autoras (2019). 
Ao analisar a distribuição dos 60 trabalhos relacionados no Quadro 1, percebe-se que em 2008 já havia quatro produções sobre a temática, com um crescente aumento na produção de dissertações nos anos subsequentes, quando comparado com a produção de teses no mesmo período. Entre as produções presentes no Quadro 1 destaca-se um maior número de dissertações do total de trabalhos selecionados.

Ao longo do período analisado o número de dissertações cresceu consideravelmente, conforme o Gráfico 1. Destacam-se os anos de 2016 e 2017 com maior número de dissertações, 2015 com maior número de teses e os anos de 2010 e 2018 com maior número de artigos.

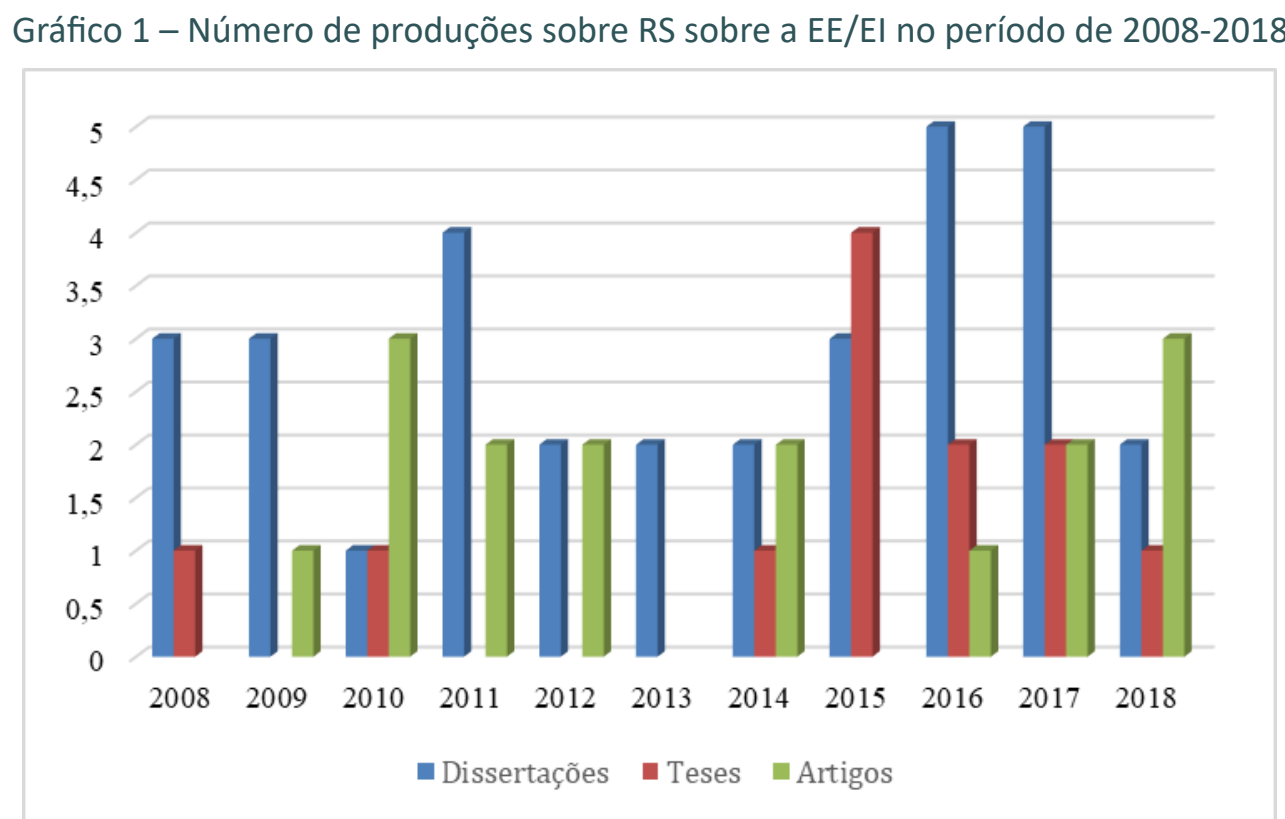

Fonte: Organizado pelas autoras (2019).

Em relação à localização das produções encontradas, foi possível elaborar a Tabela 1.

Tabela 1 - Localização das produções de RS sobre EE/El (2008-2018)

\begin{tabular}{lc}
\hline \multicolumn{1}{c}{ UNIDADES FEDERATIVAS } & $\begin{array}{c}\text { No. de } \\
\text { Produções }\end{array}$ \\
\hline São Paulo & 12 \\
Rio de Janeiro & 9 \\
Pará e Rio Grande do Sul & 8 \\
Brasília & 5 \\
Minas Gerais & 3 \\
Bahia, Goiás, Paraíba, Pernambuco, Rio Grande do Norte & 2 \\
Acre, Mato Grosso do Sul, Paraná, Santa Catarina, Sergipe & 1 \\
\hline
\end{tabular}

Fonte: Organizada pelas autoras (2019).

Entre as regiões do país, verifica-se a maior quantidade de produções na região Sudeste, com $39,3 \%$ dos trabalhos, seguida pela região SUL, com $16,4 \%$, Centro-Oeste e Norte, com $14,8 \%$ cada uma, e a região Nordeste, com 13,1\%. Destaca-se um trabalho cujo estudo é realizado em Lisboa e no Rio Grande do Norte concomitantemente. 
Os 44 trabalhos apresentados no Quadro 1, referentes às produções de teses e dissertações, vinculam-se a programas de Pós-Graduação em Educação, cujas instituições de origem ${ }^{3}$ estão apresentadas na Tabela 2:

Tabela 2 - Instituições nas quais foram realizadas as pesquisas sobre RS sobre EE/EI

\begin{tabular}{lc}
\hline \multicolumn{1}{c}{ INSTITUIÇõES DE ENSINO SUPERIOR (IES) } & $\begin{array}{c}\text { No. de } \\
\text { Produções/ } \\
\text { IES }\end{array}$ \\
\hline PUC-Goiás, PUC-SP, PUC-Rio Grande do Sul, Universidade Regional do Noroeste & \\
do Estado do Rio Grande do Sul, UE-Mato Grosso do Sul, UFBA, UFFS-Chapecó, & 1 \\
UFG, UFSM, UFSCar, UFS, UFRJ & \\
UFPE, UFRN, UFF, UFPB, UNESP (Rio Claro), UNESP (Bauru), USP & 2 \\
UE-Pará & 3 \\
UnB, UFPA, Universidade Estácio de Sá & 5 \\
\hline
\end{tabular}

Fonte: Organizada pelas autoras (2019)

Destaca-se nesse cenário que a maior quantidade de produções são advindas da Universidade Estácio de Sá, UFPA e UnB, com 5 trabalhos cada instituição.

Em relação à natureza da pesquisa, foi possível identificar a abordagem qualitativa em $82 \%$ dos estudos, a abordagem qualitativa e quantitativa em $13 \%$ dos trabalhos e $5 \%$ não especificaram a abordagem da pesquisa.

Sobre o tipo de pesquisa, na Tabela 3 é possível observar que a pesquisa de campo foi a mais utilizada nos estudos $(63,33 \%)$, seguida por trabalhos que utilizaram: estudo de caso, abordagem processual, abordagem estrutural, pesquisa-ação, pesquisa etnográfica e autobiografia.

Tabela 3 - Tipo ou abordagem da pesquisa nos trabalhos de RS sobre EE/EI

\begin{tabular}{lcc}
\hline TIPO/ABORDAGEM DA PESQUISA & No & $\%$ \\
\hline Pesquisa de campo & 38 & 63,33 \\
Estudo de caso & 7 & 10 \\
Abordagem processual & 5 & 10 \\
Abordagem estrutural & 4 & 6,69 \\
Pesquisa-ação & 3 & 5 \\
Pesquisa etnográfica & 1 & 1,66 \\
Autobiografia & 1 & 1,66 \\
Não especificado & 1 & 1,66 \\
\hline TOTAL & $\mathbf{6 0}$ & $\mathbf{1 0 0}$ \\
\hline \multicolumn{4}{c}{}
\end{tabular}

Ao realizar essa classificação, considerou-se como "Pesquisa de campo" todos os trabalhos que apresentavam dados empíricos e que utilizavam instrumentos de coleta de dados, tais como: questionários, entrevistas, grupos focais e, em muitos casos, arti-

Siglas das instituições de origem das teses e dissertações: Pontificia Universidade Católica (PUC), Universidade Estadual (UE), Universidade Federal (UF), Universidade Estadual Paulista (Unesp), Universidade de São Paulo (USP), Universidade Federal da Fronteira Sul (UFFS). 
culavam os dados empíricos com a análise de documentos como o Projeto Pedagógico do Curso (PPC) ou o Projeto Político-Pedagógico (PPP) da escola, regulamentos internos das instituições de ensino e a legislação nacional para a formação de professores.

Os trabalhos D9, D19, D20, D29 e T9 utilizaram a abordagem processual, que é própria da RS. Desta forma, os autores empregaram como base a ancoragem e objetivação, enfoque proposto por Jodelet (2001) para estudos de RSs. Os trabalhos D14, D16, T5 e T8 aplicaram a abordagem estrutural para determinar as RSs utilizando a Teoria do Núcleo Central de Abric (1998). A produção não especificada (A16) trata-se de um estudo teórico, no qual não são citados a abordagem e o tipo de pesquisa.

A partir da análise dos resumos das produções foi possível elaborar a Tabela 4, que apresenta as frequências dos instrumentos de coleta de dados utilizados.

Tabela 4 - Instrumentos e técnicas para constituição de dados utilizados nas produções de RS sobre EE/EI

\begin{tabular}{lcc}
\hline \multicolumn{1}{c}{ INSTRUMENTOS(I)/TÉCNICAS(T) } & FREQUÊNCIA & \% \\
\hline Entrevista (I) & 42 & 34,71 \\
Questionário(I) & 17 & 14,05 \\
Associação Livre de Palavras (T) & 15 & 12,40 \\
Observação (I) & 14 & 11,57 \\
Grupo Focal (T) & 8 & 6,61 \\
Caderno de Campo (I) & 3 & 2,48 \\
Análise Documental(T) & 7 & 5,79 \\
Desenhos (I) & 4 & 3,30 \\
Outros (I/T) & 11 & 9,09 \\
\hline TOTAL & $\mathbf{1 2 1}$ & $\mathbf{1 0 0}$ \\
\hline
\end{tabular}

Fonte: Organizada pelas autoras (2019).

É possível observar que os instrumentos mais utilizados foram as entrevistas, em sua maioria entrevistas semiestruturadas (27 produções) aparecendo também entrevistas abertas e episódicas. As demais produções não especificaram o tipo de entrevista.

A utilização de questionários foi a segunda opção mais usada pelos pesquisadores. Infere-se que o questionário foi utilizado pela sua facilidade de aplicação e por possibilitar atingir um maior número de participantes. Aparecem entre os tipos de questionários: semiabertos (T9), mistos (D3), socioeconômicos (T12, D12) e com frases incompletas (D16); o restante das produções não especificou o tipo de questionário. Em outros encontrou-se os seguintes instrumentos e/ou técnicas: sessão de estudos, escala de atitude, narrativa, encontros informais, mapa conceitual, enquetes, visitas, completar uma história, relatos autobiográficos e registros fotográficos.

Sobre a análise realizada, a partir dos instrumentos de constituição de dados, dos 60 estudos selecionados de RSs sobre EE/El (Tabela 5), 4 produções (A2, A10, A11, A16) configuram-se como ensaios teóricos e não apresentam metodologia de análise. 
Na Tabela 5 pode-se observar as técnicas e metodologias de análise utilizadas, predominando a análise de conteúdo, seguida da TRS; as produções justificavam a utilização dessa teoria para análise tendo em vista a perspectiva dos contextos histórico-social (T11), histórico-cultural (T10) e político/escolar (T5, D21).

Tabela 5 - Técnicas de análise de dados encontradas nos trabalhos de RS sobre EE/EI

\begin{tabular}{l|c|c}
\hline TÉCNICAS DE ANÁLISE & No & $\%$ \\
\hline Análise de Conteúdo & 32 & 53,33 \\
Abordagens Próprias da TRS & 5 & 8,33 \\
Análise do Discurso & 5 & 8,33 \\
Não Apresenta & 4 & 6,67 \\
Mapas Mentais/Conceituais & 3 & 5 \\
Análise Lexical de Classificação Hierárquica Descendente & 2 & 3,33 \\
Análise da Narrativa & 2 & 3,33 \\
Análise da Palavra & 2 & 3,33 \\
Dinâmica das 3 Características & 1 & 1,67 \\
Análise Historiográfica & 1 & 1,67 \\
Análise Lexicográfica & 1 & 1,67 \\
Análise de Classificações Múltiplas & 1 & 1,67 \\
Teoria dos Modelos Organizadores do Pensamento & 1 & 1,67 \\
\hline TOTAL & $\mathbf{6 0}$ & $\mathbf{1 0 0}$ \\
\hline
\end{tabular}

Fonte: Organizada pelas autoras (2019).

Em relação ao(s) participantes(s) da pesquisa, foi possível elaborar a Tabela 6, em que se verifica que das 60 produções encontradas, apenas no A16 não houve participantes.

Tabela 6 - Participantes de pesquisa encontrados nos trabalhos de RS e EE/EI

\begin{tabular}{lll}
\hline PARTICIPANTES DA PESQUISA & PRODUÇÕES & $\%$ \\
\hline Professores do Ensino Fundamental I e II & $\begin{array}{r}\text { D1, D2, D3, D5, D7, D10, D12, D20, } \\
\text { D21, D23, D25, D26, D29, D32, T2, T3, } \\
\text { T4, T5, T11, A1, A7, A8, A12 }\end{array}$ & \\
\hline PCD/Alunos com NEE & D8, D9, D13, D19, D31, T6, T7, T9, A11 & 13,43 \\
\hline Outros & D4, D8, D16, T6, A2, A9, A13, A15 & 11,94 \\
\hline Professores em Formação Inicial & D6, D17, D22, T1, T8, T12, A4, A5 & 11,94 \\
\hline Alunos sem NEE/Deficiência & D30, T10, A3, A6, A14 & 7,46 \\
\hline Professores do Ensino Médio & D11, D14, D15, D24 & 5,97 \\
\hline Professores do Ensino Superior & D28, T6, T12 & 4,48 \\
\hline $\begin{array}{l}\text { Professores Atendimento Educacional } \\
\text { Especializado }\end{array}$ & D20, D27, A15 & 4,48 \\
\hline Comunidade Escolar & D18, D30, A10 & 4,48 \\
\hline $\begin{array}{l}\text { Professores da Educação de Jovens e } \\
\text { Adultos (EJA) }\end{array}$ & T2 & 2,98 \\
\hline TOTAL & $\mathbf{6 7}{ }^{4}$ & $\mathbf{1 0 0}$ \\
\hline
\end{tabular}

Fonte: Organizada pelas autoras (2019).

\footnotetext{
${ }_{4}^{4}$ A quantidade de participantes é maior do que o número de produções totais, pois algumas pesquisas havia mais de um tipo de participante.
} 
É possível observar que a maior parte das produções teve como participantes das pesquisas professores (64,8\%); destes, destaca-se a quantidade concentrada de produções com professores do Ensino Fundamental I e II (quase $50 \%$ das produções). Depreende-se que essa representatividade se caracteriza, tendo em vista que, segundo os dados estatísticos do Censo Escolar de 2018, grande parte do público-alvo da EE está nas classes iniciais do Ensino Fundamental, onde ocorre a atuação desses profissionais (BRASIL, 2018), e identificar a RS destes professores contribui para compreender as dificuldades para se efetivar a inclusão escolar. Quanto aos professores em formação inicial, os cursos abordados nas produções foram: Pedagogia (T8, T9, A4), Educação Física (D6, T1, A5), Letras-Libras (D17) e Química (D22).

Nesse caso, considera-se que, em virtude da relevância da temática EE/El na formação de professores, o fato da pequena diversidade de cursos de Licenciatura constitui uma lacuna nas pesquisas de RS sobre a EE/EI.

Em relação aos participantes das pesquisas caracterizados como "PCD/Alunos com NEE", há produções com alunos surdos (D8, D9, D19, T9, A9), alunos com deficiência visual (D13, A11), alunos com deficiência física (T7) e PCD/NEE (D31, T6) sem especificação da deficiência.

Sobre a categoria "Outros" foram encontradas pesquisas com familiares, como a D4, que aborda as mães de alunos com NEE; o artigo A13, que tem como participantes as famílias no geral; o artigo A15, que aborda apenas os pais; a tese T6, que aborda as RSs de comunidades; o artigo A9, que aborda uma comunidade indígena, a dissertação D8, com intérpretes de Libras, e A2 com coordenadores da Educação Infantil.

No geral é possível observar os mais variados tipos de participantes de pesquisa, o que evidencia que as produções são abrangentes quanto à constituição de dados para a construção das RSs. Destacam-se, entre essas, a tese T6, que abordou o maior número de participantes, entre eles: professores, pessoas com deficiência/NEE e a comunidade. Entre o público-alvo da $E E$, os únicos participantes não abordados, em específico, foram alunos com altas habilidades/superdotação, e alunos com transtornos globais do desenvolvimento. Talvez estejam inclusos em trabalhos como D31, que descreve os participantes da pesquisa como "pessoas com deficiência e com outras necessidades educacionais específicas" sem especificá-las, e/ou a produção T6, que descreve como participantes da pesquisa professores e não professores, igualmente sem especificá-los.

Para a análise dos objetivos das 60 produções encontradas no Quadro 1, utilizou-se a análise de conteúdo de Bardin (2016), e foi possível elencar duas categorias, de acordo com os objetivos do trabalho em relação à RS almejada. São elas: 1) EE/EI e 2) Público-alvo da EE.

Para a categoria EE/El são elencadas as produções que abordam em seus objetivos a RS sobre os processos envolvidos na inclusão de alunos. Esses trabalhos discutem as RSs sobre a inclusão dos alunos com NEE a despeito da acessibilidade nos recursos materiais, na capacitação de profissionais, nas relações atitudinais envolvidas no atendimento ao público-alvo da EE/El em seu processo de escolarização, tanto suplementado quanto em salas regulares. Os excertos dessa categoria foram analisados por meio de três subcategorias, organizadas no Quadro 2. 
Quadro 2 - Objetivos das produções encontradas

\begin{tabular}{|l|l|l|c|}
\hline CATEGORIA & SUBCATEGORIAS & FONTE DOS DADOS & TOTAL \\
\hline \multirow{5}{*}{ 1) EE/EI } & \multirow{2}{*}{ a) Inclusão Escolar } & $\begin{array}{l}\text { T5, T6, T12, D1, D4, D5, D7, D12, D13, } \\
\text { D15, D19, D21, D22, D24, D25, D26, } \\
\text { D28, D29, A1, A2, A5, A7, A10, A13 }\end{array}$ & 24 \\
\cline { 2 - 4 } & $\begin{array}{l}\text { b) Processos Formativos para } \\
\text { EE/EI }\end{array}$ & $\begin{array}{l}\text { T1, T2, T3, T7, T11, D2, D6, D16, D20, } \\
\text { D23, D27, A16 }\end{array}$ & 12 \\
\cline { 2 - 4 } & $\begin{array}{l}\text { c) Inserção Profissional/ } \\
\text { Projetos de Vida }\end{array}$ & T9, D9, D31, D32, A11 & 5 \\
\hline \multirow{5}{*}{$\begin{array}{l}\text { 2) Público- } \\
\text { Alvo da EE }\end{array}$} & a) PCD/Aluno com NEE & T8, D3, D11, D18, A4, A6, A9 & 7 \\
\cline { 2 - 4 } & b) Surdo(s) & D8, D10, D17, D30, A3 & 5 \\
\cline { 2 - 4 } & c) Deficiência Intelectual & T10, A8, A12, A15 & 2 \\
\cline { 2 - 4 } & d) Deficiência Física & T4, A14 & 1 \\
\cline { 2 - 4 } & $\begin{array}{l}\text { e) Altas Habilidades/ } \\
\text { Superdotação }\end{array}$ & D14 & 60 \\
\hline TOTAL & \multicolumn{2}{|l}{}
\end{tabular}

Fonte: Organizado pelas autoras (2019).

A subcategoria a) Inclusão Escolar, teve a maior frequência, com 24 produções. Nesta subcategoria foram caracterizadas as produções que apresentam como objetivo identificar a RS a despeito da inclusão, como demonstrado nos excertos a seguir:

T5: [...] o objetivo deste estudo foi investigar as representações sociais de professores acerca da inclusão escolar (grifo nosso).

D4: [...] conhecer as representações sociais das mães sobre a inclusão vivenciada por seus filhos com deficiência no contexto da rede pública de Ensino Fundamental do município de João Pessoa (grifo nosso).

Na subcategoria b) Processos Formativos, foram identificadas 12 produções que traziam em seus objetivos o estudo da RS sobre os processos formativos para EE/El, sejam eles referentes à formação de professores da Educação Básica (Ensino Fundamental, Médio e Técnico), formação inicial e formação continuada, conforme os trechos a seguir:

D2: Esta pesquisa tem como objetivo estudar as representações sociais de professores acerca da formação continuada em Educação Especial (grifo nosso).

T3: Cujo objetivo voltou-se a identificar a influência da formação continuada na (re)construção das representações sociais de educação inclusiva e de alunos com deficiência dos professores do Ensino Fundamental (grifo nosso).

A16: Discute a cultura de colaboração entre os professores sob a perspectiva das representações sociais estereotipadas e a função dos educadores frente à escolarização de alunos com deficiências (grifo nosso).

Na subcategoria c) Inserção Profissional/Projetos de Vida, foram identificados cinco trabalhos que buscaram identificar a RS sobre a inserção profissional, futuro profissional e/ou projetos de vida da PCD, conforme os excertos:

D9: Essa pesquisa teve como objetivo investigar representações sociais de universitários surdos sobre inserção profissional (grifo nosso).

T9: Analisar a constituição das Representações Sociais de Surdos universitários acerca dos processos de escolarização e as repercussões em seus projetos de vida (grifo nosso). 
Para a segunda categoria "Público-Alvo da EE", tem-se as produções que abordam em seus objetivos as RSs sobre os aspectos que definem a inserção de um aluno na EE.

A despeito dessa categoria de análise foram encontradas 19 produções, que tratam em seus objetivos da identificação da RS sobre a(s) deficiência(s) em geral, ou em específico, como destacado no Quadro 2. Veja-se os trechos a seguir:

T8: Esta pesquisa teve como objetivo compreender as representações sociais de "pessoa com deficiência" dos estudantes dos cursos de Pedagogia, de Instituições de Ensino Superior da cidade do Recife e Região Metropolitana (grifo nosso).

D10: O objetivo geral é analisar as representações sociais de professores do Ensino Fundamental sobre o aluno surdo e a influência destas na prática pedagógica inclusiva em uma escola regular da Rede Municipal de Ensino (RME) de Ananindeua - Pará (grifo nosso).

T10: [...] o objetivo principal deste trabalho foi o de conhecer e analisar as representações sociais que os jovens de Ensino Médio (EM) têm sobre deficiência intelectual (grifo nosso).

Tendo em vista que essa revisão sistemática tem como foco as representações sociais sobre $\mathrm{EE} / \mathrm{EI}$, foram analisados os resultados das pesquisas que tinham esse objetivo geral, totalizando 41 produções (Quadro 2).

Dessa maneira, a análise dos resultados dos trabalhos referentes à RS sobre a EE/ $\mathrm{El}$, emergiram quatro categorias, conforme o Quadro 3.

Quadro 3 - Resultados das produções sobre a RS de EE/EI

no contexto da formação de professores

\begin{tabular}{|c|c|c|c|}
\hline $\begin{array}{l}\text { CATEGORIA DE } \\
\text { ANÁLISE }\end{array}$ & PRODUÇÕES & EXEMPLOS & TOTAL \\
\hline $\begin{array}{l}\text { RSs } \\
\text { Excludentes }\end{array}$ & $\begin{array}{l}\text { D1, D2, D4, } \\
\text { D5, D23, D25, } \\
\text { D26, D28, } \\
\text { D29, T5, T7, } \\
\text { T11, A1, A2, } \\
\text { A5, A10, A13, } \\
\text { A16 } \\
\end{array}$ & $\begin{array}{l}\text { D1: Os dados indicam que a situação de inserção do aluno com } \\
\text { deficiência ameaça a segurança dos professores, em termos } \\
\text { de vigília e de controle. Apontam-se indícios da condição de } \\
\text { isolamento do aluno com deficiência, localizado nas primeiras } \\
\text { carteiras e vigiado em suas atitudes e comportamentos (grifo } \\
\text { nosso). }\end{array}$ & 18 \\
\hline RSs Mistas & $\begin{array}{l}\text { D7, D9, D12, } \\
\text { D13, D15, } \\
\text { D16, D20, } \\
\text { D21, D31, } \\
\text { D32, T2, T9, } \\
\text { A7 }\end{array}$ & $\begin{array}{l}\text { D9: Os significados expressos nas entrevistas indicam o } \\
\text { conflito entre duas posições [...] por um lado, entre as pessoas } \\
\text { que se comunicam majoritariamente em língua portuguesa } \\
\text { dominante no ambiente de trabalho parece prevalecer a visão } \\
\text { clínica da surdez, em que o surdo é visto como deficiente; por } \\
\text { outro lado, entre os surdos prevalece o enfoque mais atual } \\
\text { identificado com as culturas surdas (grifo nosso). }\end{array}$ & 13 \\
\hline $\begin{array}{l}\text { RSs } \\
\text { Ressignificadas }\end{array}$ & $\begin{array}{l}\text { D6, D19, D22, } \\
\text { D24, D27, T1, } \\
\text { T3 }\end{array}$ & $\begin{array}{l}\text { T3: Notamos que embora os docentes critiquem o caráter } \\
\text { estanque e limitado dos cursos de formação continuada que } \\
\text { têm frequentado, revelam representações sociais de educação } \\
\text { inclusiva e de aluno com deficiência, embasados nas teorias e } \\
\text { conceitos advindos de tais cursos, o que caracteriza a formação } \\
\text { continuada como um dos elementos que influenciam seus } \\
\text { discursos e ações (grifo nosso). }\end{array}$ & 7 \\
\hline RSs Inclusivas & T6, T12, A11 & $\begin{array}{l}\text { T6: O predomínio de representações favoráveis à inclusão de } \\
\text { Pessoas com Deficiência na Educação Superior nos contextos } \\
\text { empíricos investigados sugere um avanço conceitual e nas práticas } \\
\text { educacionais com relação à educação inclusiva (grifo nosso). }\end{array}$ & 3 \\
\hline TOTAL & & & 41 \\
\hline \multicolumn{4}{|c|}{ Fonte: Organizado pelas autoras (2019). } \\
\hline
\end{tabular}


A categoria "RS Excludente" refere-se às produções cujos resultados apontaram RSs que não favorecem a inclusão; as "RS mistas" referem-se aos resultados em que as RSs foram excludentes em alguns aspectos e inclusivas em relação a outros; a categoria "RSs Ressignificadas" são aquelas que por meio de uma intervenção (seja um curso, ou uma disciplina, entre outros) as RSs sobre inclusão foram ressignificadas e a categoria "RS Inclusiva" diz respeito às produções que tiveram como resultados RSs que favorecem a inclusão.

Desta forma, a partir do Quadro 3 pode-se observar que a maior parte das representações encontradas foram consideradas como as que não contribuem para inclusão.

Nesse sentido, concordamos com Dutra e Griboski (2006) sobre os processos envolvidos na inclusão, que vão ao encontro da TRS:

A inclusão expressa uma dimensão de direitos humanos e justiça social que pressupõe o acesso pleno e a participação de todos nas diferentes esferas da estrutura social, a garantia de liberdades e direitos iguais e o estabelecimento de princípios de eqüidade. Essa concepção situa-se na perspectiva de uma sociedade democrática e na compreensão do caráter social das relações, considerando a capacidade humana de desenvolver valores de dignidade e cidadania, de respeitar esses pressupostos e de modificá-los na construção do processo social (p. 209).

Assim, para analisar o motivo pelo qual grande parte das produções resultou em RSs sobre a EE/El excludentes, analisou-se as produções que apresentaram como resultado "RSs excludentes" e "RSs mistas" (31 produções no total), buscando identificar quais aspectos da inclusão que se constituíram os maiores desafios enfrentados para $\mathrm{EE} / \mathrm{El}$. Nesse sentido, verificou-se que foram os aspectos relativos às dimensões de acessibilidade (SASSAKI, 2009) e às necessidades formativas de professores para a inclusão de alunos com NEE (NOZI, 2013).

Desse modo, identificou-se nas produções as seguintes dimensões de acessibilidade consideradas barreiras para a inclusão: 1) RS excludente sobre atitudes e emoções; 2) RS excludente diante dos procedimentos; 3) RS excludente diante das características de alunos com NEE/PCD.

As "RSs Excludentes Sobre Atitudes e Emoções" foram encontradas em 11 produções (D1, D3, D4, D7, D12, D28, T7, T9, A1, A7, A16) que trouxeram a RS sobre EE/ El como resultante de atitudes: pessoa-pessoa, pessoa-instituição e vice-versa, assim como de emoções vinculadas à PCD e ao aluno com NEE. Esta barreira à inclusão envolve as dimensões atitudinais descritas por Sassaki (2009) e Nozi (2013), as quais são expressas nos excertos:

T7: Sobre o contexto social, na relação aluno-aluno, os participantes vivenciaram situações nas quais o preconceito, o estereótipo e a agressão estiveram presentes; na relação professor-aluno houve representações de situações positivas (acolhimento, atendimento às necessidades, defesa contra o bullying) e situações negativas (preconceito, indiferença, agressão) (grifo nosso).

A1: $O$ caráter afetivo das evocações se sobressai nas representações sociais do educando com deficiência afetando o significado de inclusão enquanto direito do aluno com deficiência. Assim, a Educação Especial, apesar de seus méritos formais, enquanto direito social garantido constitucionalmente às pessoas com deficiência, continua sendo negada (grifo nosso). 
É possível observar que, entre as representações excludentes apresentadas, o caráter afetivo é constituinte dos aspectos envolvidos na EE/EI, e nesse sentido concorda-se com Rouquette (2003):

Se considerarmos que uma representação se é um conhecimento estruturado que tem um papel determinante no modo como os indivíduos vêm e reagem face à realidade, fica evidente que este conhecimento é dotado de cargas afetivas, é atravessado (ou poderia se dizer, "ativado") por um componente afetivo (p. 436).

Esse componente afetivo "ativado" acaba por reproduzir a exclusão na dimensão atitudinal, que se expressa em discursos como de "trabalho penoso", em que representações são dissociadas em forma de preconceitos e estereótipos. Nesse intento, conforme Alves e Souza (2004), é necessário pensar num processo de reestruturações

[...] perceptivas e afetivo-emocionais que interfiram nas predisposições de cada um de nós com relação à alteridade, dispensando-se rótulos e examinando-se as relações entre as incapacidades das pessoas e as barreiras a elas interpostas pela conjuntura da sociedade em que vivemos (p. 123).

Sobre as "2) RSs Excludentes Frente aos Procedimentos", encontrou-se 12 produções (D2, D13, D20, D21, D26, D29, D31, D32, T5, A2, A10, A13) que em seus resultados apontaram a RS construída atrelada aos procedimentos educacionais, conforme os excertos:

D2: O tratamento do material coletado deixou ver indícios da presença forte de dois polos, articulando os sentidos atribuídos ao objeto pelos sujeitos: o primeiro, mais denso, gira em torno da frustração dos professores com os programas de formação continuada, que ratificam para os docentes a desvalorização de si: desconhecendo as efetivas condições de trabalho locais, atendo-se a conteúdos e procedimentos predefinidos sem qualquer participação dos destinatários na elaboração e execução dos programas; o segundo é o sentimento de angústia ligado ao despreparo dos professores, por desconhecerem o que julgam ser o mínimo necessário para atuarem com as diferenças e ausência de apoio e envolvimento dos gestores, que resumem sua atuação em procedimentos formais, mas sem o comprometimento com práticas inclusivas mais extensas, que garantam condições de trabalho ao professor (grifo nosso).

A13: Os resultados demonstraram que na avaliação das mães entrevistadas as políticas, mesmo não universalizadas, com indícios de que precisam melhor atender aos alunos com deficiência intelectual (DI), colaboram para a vida escolar dos alunos (grifo nosso).

Essa subcategoria de análise expressa muito dos resultados históricos de exclusão vivenciados pelo público da $\mathrm{EE}$, e envolve os processos de efetivação das políticas de inclusão. Nisto pode-se observar, como já mencionado anteriormente, que a constituição de direitos ao público da EE não é suficiente para que de fato, na realidade escolar se efetive a inclusão, pois

[...] quando a legislação garante acesso a todos, a permanência começa a ser fragilizada, pois novos mecanismos de seleção são criados, os índices de aprovação/ reprovação servem como indicadores para verificar quem são os excluídos da vez (FONSECA; PIMENTA, 2012, p. 2). 
Para as "3) RSs excludentes frente às características dos alunos com NEE/PCD", foram identificadas oito produções (D5, D9, D15, D16, D25, T2, T11, A5) que, embora não considerem em seus objetivos as características de alunos com NEE e/ou PCD - categoria de objetivos supracitada nessa pesquisa - trouxeram em seus resultados RSs excludentes, constituídas com base nas características desse público, denotando como "corpos diferentes" de uma tipificação de normalidade, as quais podem ser observadas nos trechos:

D15: Constatamos ainda que a experiência de escolarização do aluno com DI vem impactando os professores de Ensino Médio, mas essa experiência é compartilhada, principalmente, por meio da prática de lamentação, que promove o alívio do mal-estar, mas não permite ampliar as crenças dos professores na capacidade de desenvolvimento desses alunos. Isso acaba por perpetuar uma representação social centrada exclusivamente na ideia de dificuldade e imutabilidade da deficiência (grifo nosso).

T11: O material analisado permitiu concluir que, ainda que tenham ocorrido expressivas mudanças na representação do surdo no espaço entre a legislação de reconhecimento da Libras, de 2002 até o presente momento, as representações sociais dos surdos como deficientes ainda não foram totalmente abandonadas, e encontram-se em movimento dinâmico, característica ressaltada por Moscovici (2012) (grifo nosso).

Nesse sentido, a função de comunicação e respectiva classificação de uma RS, a qual Moscovici (1978) estabelece em sua teoria como um sistema de valores que um grupo realiza no processo de tornar o "não familiar" em "familiar", não considera "a estrutura social uma decorrência de leis históricas, nem as limitações ou capacidades humanas como condições inalteradas" (DUTRA; GRIBOSKI, 2006, p. 209).

\section{CONSIDERAÇÕES FINAIS}

O objetivo deste trabalho foi realizar uma revisão sistemática de literatura das RSs sobre a EE/El, no período de 2008-2018, tendo como base de dados o catálogo de dissertações e teses da Capes e os periódicos disponíveis on-line do Qualis Educação (estratos A1, A2, B1). De maneira geral, foi possível observar que muitas pesquisas têm sido realizadas nos últimos anos, e o número de publicações vem aumentando no período considerado. Constatou-se que as localidades em que as produções foram realizadas abrangem todas as áreas do Brasil, distribuídas entre instituições privadas e públicas, estaduais e federais.

A despeito da natureza da pesquisa, a grande maioria se utiliza da abordagem qualitativa, como a pesquisa de campo, o que era esperado tendo em vista que as representações sociais são definidas como o conjunto de explicações, crenças e ideias que nos permitem evocar um dado acontecimento, pessoa ou objeto. Estas representações são resultantes da interação social e por isso são comuns a um determinado grupo de indivíduos.

Sobre os instrumentos e técnicas para constituição de dados, constatou-se que a maior parte das produções utiliza mais de um instrumento, destacando-se neste contexto a entrevista semiestruturada. Na identificação das RSs foi possível observar a utilização da técnica de Associação Livre de Palavras (ALP) em poucas produções, e a escala de atitude, que também é recomendável para compreensão das representações, foi utilizada em apenas uma produção. 
Para a análise dos dados foi possível observar que grande parte dos trabalhos utilizou a análise de conteúdo, apenas seis produções empregaram a abordagem estrutural ou a abordagem processual, próprias da TRS. Neste contexto, a análise de discurso também poderia ser mais utilizada, visto que as RSs são produto das relações sociais realizadas por meio da comunicação.

Constatou-se que as produções abordaram uma diversidade de participantes em suas pesquisas, atingindo a maior parte da comunidade escolar: professores do Ensino Fundamental, Médio, Superior, AEE, EJA, coordenadores, diretores e alunos com NEE. Referente a este último grupo, não houve registro de participação de alunos com altas habilidades/superdotação e alunos com deficiência intelectual. Da comunidade em geral foram observados relatos de mães, familiares, comunidade indígena e professores em formação inicial. Referentes a este último grupo de participantes, destacam-se os cursos de Pedagogia, Educação Física, Letras-Libras e Química. Já estudos no contexto da formação inicial nas demais áreas de conhecimento foram considerados uma lacuna.

Em relação aos objetivos das produções, foi possível verificar que estes buscavam, em sua maioria, identificar as RSs sobre a inclusão dos alunos com NEE ou identificar as RSs sobre os processos formativos para a inserção de alunos da EE.

Os resultados das pesquisas realizadas apontaram, em sua maioria, que as RSs não favorecem o processo de inclusão, e que as principais barreiras são a acessibilidade atitudinal e metodológica.

Conclui-se que a exclusão ainda é preponderante na maioria dos discursos dos diversos atores sociais na área educacional, não só devido à falta de efetivação de políticas públicas, mas principalmente pela representação do senso comum sobre a $P C D$, que tem sido historicamente reproduzida e compartilhada pela sociedade. Nesse sentido, considera-se que as RSs apresentam contribuições relevantes para repensar os fatores fundamentais para construção de uma escola democrática, e consequentemente, de uma sociedade que ressignifique a forma de interagir com o público-alvo da Educação Especial promovendo uma Educação Inclusiva.

\section{REFERÊNCIAS}

ABRIC. A abordagem estrutural das representações sociais. In: MOREIRA, A. S. P.; OLIVEIRA, D. C. (org.). Estudos interdisciplinares de representação social. Goiânia: AB, 1998. p. 27-46.

ALMEIDA, S. A.; NAIFF, L. A. M. Inclusão educacional nas representações sociais de professores e estudantes de Magistério. Pesquisas e Práticas Psicossociais, São João Del-Rei, v. 6, n. 1, p. 29-38, 2011.

ALVES, M. D.; SOUZA, C. R. S. E. Rompendo barreiras atitudinais: um caminho de aproximação com o outro "diferente". Vidya, Centro Universitário Franciscano, Santa Maria, v. 21, n. 38, p. 119-124, jul. dez. 2004.

BARDIN, L. Análise de conteúdo. São Paulo: Edições 70, 2016.

BRASIL. Lei no. 9394, de 20 de dezembro de 1996. Dispõe sobre as Diretrizes e Bases da Educação Nacional. Diário Oficial [da] República Federativa do Brasil, Brasília, DF, 23 dez. 1996. Disponível em: <http:// www.planalto.gov.br/ccivil_03/leis/I9394.htm>. Acesso em: 29 dez. 2019.

BRASIL. Ministério da Educação, Secretaria de Educação Especial. Decreto no 6.751, Institui as Diretrizes Operacionais da Educação Especial para o Atendimento Educacional Especializado - AEE na educação básica Política Nacional de Educação Especial na Perspectiva da Educação Inclusiva. Brasília, DF, jan. 2008. Disponível em: http://portal.mec.gov.br/index.php?option=com_docman\&view=download\&alias=428-diretrizes-publicacao\&Itemid=30192. Acesso em: 29 dez. 2019. 
BRASIL. Notas estatísticas. Censo Escolar 2018. Instituto Nacional de Estudos e Pesquisas Educacionais. Brasília - DF. Disponível em: http://download.inep.gov.br/educacao_basica/censo_escolar/notas_estatisticas/2018/notas_estatisticas_censo_escolar_2018.pdf. Acesso em: 18 dez. 2019.

$\mathrm{DECHICHI}, \mathrm{C}$. Transformando o ambiente da sala de aula em um contexto promotor do desenvolvimento do aluno deficiente mental. 2001. 245 f. Tese (Doutorado em Psicologia da Educação) - Pontifícia Universidade Católica de São Paulo, São Paulo, 2001.

DUTRA, C. P.; GRIBOSKI, C. M. E. Educação inclusiva: um projeto coletivo de transformação educacional. In: SEMINÁRIO NACIONAL DE FORMAÇÃO DE GESTORES E EDUCADORES. ENSAIOS PEDAGÓGICOS. 3., 2006. Brasília: Ministério da Educação; Secretaria de Educação Especial, 2006.

FONSECA, J. A. L.; PIMENTA, R. W. A chegada dos desiguais à escola: novas formas de inclusão/exclusão. ANPED SUL: SEMINÁRIOS DE PESQUISA EM EDUCAÇÃO DA REGIÃO SUL, 4., 2012. Caxias do Sul - RS, 2012. Disponível em: http://www.ucs.br/etc/conferencias/index.php/anpedsul/9anpedsul/paper/viewFile/2796/421. Acesso em: 10 jan. 2020.

GILLY, M. As representações sociais no campo educativo. Trad. S. M. F. Ranzi e M. C. Silva. Educar, Curitiba, n. 19, p. 231-252, 2002.

GLAT, R. Desconstruindo representações sociais: por uma cultura de colaboração para a inclusão escolar. Revista Brasileira Educação Especial, Marília, v. 24, Edição Especial, p. 9-20, 2018.

GODOY, A. S. Pesquisa qualitativa: tipos fundamentais. Revista de Administração de Empresas, São Paulo, v. 35, n. 3, p. 20-29, maio/jun. 1995.

LAKATOS, E. M.; MARCONI, M. de A. Fundamentos de metodologia científica. 5. ed. São Paulo: Atlas, 2003. JODELET, D. Representações Sociais: um domínio em expansão. In: JODELET, D. As representações sociais. Tradução Lilian Ulup. Rio de Janeiro: Eduerj. 2001.

MAZZOTTA, M. J. S. Educação especial no Brasil: história e políticas públicas. São Paulo: Cortez, 1996.

MEGID NETO, J. Tendências da pesquisa acadêmica sobre o ensino de ciências no Nível Fundamental. 1999. 114 f. Tese (Doutorado em Educação) - Universidade Estadual de Campinas, Programa de Pós-Graduação em Educação, 1999.

MEGID NETO, J.; CARVALHO, L. M. Pesquisas de Estado da Arte: fundamentos, características e percursos metodológicos. In: ESCHENHAGEN, M. L.; VÉLEZ-CUARTAS, G.; MALDONADO, C. P.; GUERRO, G. (org.). Construcción de problemas de investigación: diálogos entre el interior y el exterior. Medellín, Colombia, Sudamérica: Fondo Editorial FSCH; Universidad Pontificia Bolivariana; Universidad de Antioquia, 2018.

MOSCOVICl, Serge. A representação social da psicanálise. Rio de Janeiro: Zahar, Brasília, 1978.

NOZI, G. S. Análise dos saberes docentes recomendados pela produção acadêmica para a inclusão escolar de alunos com necessidades educacionais especiais. 2013. 181 f. Dissertação (Mestrado em Educação) Universidade Estadual de Londrina, Centro de Educação, Comunicação e Artes, Programa de Pós-Graduação em Educação, 2013.

OLIVEIRA, D. C. Análise de conteúdo temático-categorial: uma proposta de sistematização. Revista Enfermagem, Rio de Janeiro: Uerj, 16(4), p. 569-76, out./dez. 2008.

OLIVEIRA, L. C. Visibilidade e participação política: um estudo no Conselho Municipal da Pessoa com Deficiência em Niterói Dissertação (Mestre em Serviços Sociais) - PUC-Rio, Rio de Janeiro, RJ, 2010.

ROMANOWSKI, J. P.; ENS, R. T. As pesquisas denominadas do tipo "Estado da Arte". Diálogos Educacionais, v. 6, n. 6, p. 37-50, 2006.

ROUQUETTE, M. L. As representações sociais no quadro geral do pensamento social. In: MOREIRA, A. S. P. et al. Perspectivas teórico-metodológicas em representações sociais. João Pessoa: Ed. UFPB, 2003.

SASSAKI, R. K. Inclusão, o paradigma da próxima década. Mensagem, Brasília, v. 34, n. 83, p. 29, 1998.

SASSAKI, R. K. Inclusão: acessibilidade no lazer, trabalho e educação. Revista Nacional de Reabilitação

(Reação), São Paulo, a. XII, p. 10-16. mar./abr. 2009. Disponível em: https://files.cercomp.ufg.br/weby/ up/211/o/SASSAKI_-_Acessibilidade.pdf?1473203319. Acesso em: 5 jan. 2020.

SILVA, M. O. E. Da exclusão à inclusão: concepções e práticas. Revista Lusófona da Educação, n. 13, p. 135153, 2009.

VASCONCELLOS, K. M.; SANTOS, M. F. S.; ALMEIDA, A. M. O. A representação social do aluno com deficiência na educação inclusiva: o olhar das crianças. Práxis Educativa, Ponta Grossa, v. 6, n. 2, p. 277-287, jul./dez. 2011. 